\title{
Dimensional compatibility and limitations of tracheal intubation through supraglottic airway devices: a mannequin-based in vitro study
}

\section{Compatibilité dimensionnelle et limitations de l'intubation trachéale avec des dispositifs supraglottiques : une étude in vitro sur mannequin}

\author{
Berthold Moser, MD • Michael Kemper, MD • Maren Kleine-Brueggeney, MD, PhD • \\ Lukas Gasteiger, MD (D) - Markus Weiss, MD
}

Received: 2 January 2021 / Revised: 14 March 2021 / Accepted: 16 March 2021 / Published online: 20 May 2021

(C) The Author(s) 2021

\begin{abstract}
Background Flexible bronchoscope-guided tracheal intubation through supraglottic airway devices (SGAs) is a well-established element of difficult intubation algorithms. Success can be limited by dimensional incompatibilities between tracheal tubes (TTS) and SGAs. Methods In this in vitro study, we tested the feasibility of TT passage through SGAs, removal of SGAs over TTs, and the ability to guide the flexible bronchoscope with 13 TT brands (internal diameter, 6.5-8.0 $\mathrm{mm}$ ) and ten different SGAs (\#4 and \#5) in an intubation mannequin.

Results We tested 1,040 combinations of SGAs and TTs. Tracheal tube passage failed in 155 (30\%) combinations of the five tested first-generation SGAs (117 [46\%] with SGA
\end{abstract}

Electronic supplementary material The online version of this article (https://doi.org/10.1007/s12630-021-01993-5) contains supplementary material, which is available to authorized users.

B. Moser, MD $\cdot$ L. Gasteiger, MD $(\bowtie)$

Department of Anaesthesia and Intensive Care, Medical

University of Innsbruck, Anichstraße 35, 6020 Innsbruck,

Austria

e-mail: lukas.gasteiger@tirol-kliniken.at

M. Kemper, MD

Department of Anaesthesiology, University Children's Hospital Zurich, Zürich, Switzerland

Department of Anaesthesiology, RWTH Aachen University Hospital, Aachen, Germany

M. Kleine-Brueggeney, $\mathrm{MD}, \mathrm{PhD} \cdot \mathrm{M}$. Weiss, $\mathrm{MD}$

Department of Anaesthesiology, University Children's Hospital

Zurich, Zürich, Switzerland
\#4, 38 [15\%] with SGA \#5) and in three (0.6\%) combinations of the five tested second-generation SGAs (two [0.8\%] with SGA \#4 and one [0.4\%] with SGA \#5). The reason for failed passage of a TT through a firstgeneration SGA consistently was a too-narrow SGA connector. Removal of the SGA over the TT in the 882 remaining combinations was impossible for all sizes of reinforced TTs, except the Parker Reinforced TT, and was possible for all non-reinforced TTs. Only one combination with SGA \#4 and 84 combinations with SGA \#5 were not ideal to adequately guide the flexible bronchoscope.

Conclusion Clinically relevant combinations of adult-size TTs and SGAs can be incompatible, rendering flexible bronchoscope-guided tracheal intubation through an SGA impossible. Additional limitations exist regarding removal of the SGA and maneuverability of the flexible bronchoscope.

\section{Résumé}

Contexte L'intubation endotrachéale guidée par bronchoscope flexible via un dispositif supraglottique (DSG) est un elément établi des algorithmes utilisés pour les intubations difficiles. La réussite de l'intubation peut être limitée par des incompatibilités dimensionnelles entre les tubes endotrachéaux (TET) et les DSG.

Méthode Dans cette étude in vitro, nous avons testé la faisabilité de faire passer un TET par un DSG, le retrait du DSG par-dessus le TET et la possibilité de guider un bronchoscope flexible avec 13 marques de TET (diamètre interne, 6,5-8,0 mm) et dix DSG différents (\#4 et \#5) sur un mannequin d'intubation. 
Résultats Nous avons testé 1040 combinaisons de DSG et de TET. Le passage du tube endotrachéal a échoué dans 155 (30\%) combinaisons avec les cinq DSG de première génération testés (117 [46 \%] avec DSG \#4, 38 [15\%] avec DSG \#5) et dans trois (0,6\%) combinaisons avec les cinq DSG de deuxième génération testés (deux [0,8\%] avec DSG \#4 et une [0,4\%] avec DSG \#5). La raison de l'échec du passage d'un TET à travers un DSG de première génération était systématiquement liée à un connecteur de DSG trop étroit. Dans les 882 combinaisons restantes, le retrait du DSG par-dessus le TET s'est avéré impossible avec toutes les tailles de TET armés, à l'exception du TET armé Parker, et était possible avec tous les TET non armés. Une seule combinaison avec le DSG \#4 et 84 combinaisons avec le DSG \#5 n'étaient pas idéales pour guider le bronchoscope flexible de manière adéquate.

Conclusion Les combinaisons cliniquement pertinentes de TET et de DSG de tailles adultes peuvent être incompatibles, rendant impossible l'intubation endotrachéale guidée par bronchoscope flexible via un DSG. D'autres limites existent en ce qui concerne le retrait du DSG et la maniabilité du bronchoscope flexible.

Keywords supraglottic airway device $\cdot$ tracheal tube . flexible bronchoscope $\cdot$ intubation $\cdot$ tracheal

Tracheal intubation through supraglottic airway devices (SGA) is a is a well-established element of algorithms for the management of the unanticipated difficult airway. ${ }^{1-4}$ Algorithms emphasize the importance of flexible bronchoscope guidance, since blind intubation through SGAs is associated with low success rates. ${ }^{5}$ Flexible bronchoscope-guided intubation through an SGA is a procedure that is easy to learn and perform with high success rates and is therefore the recommended technique. ${ }^{5-7}$

Tracheal intubation through an SGA may be hampered by dimensional incompatibilities, such as a mismatch of the internal diameter (ID) of the SGA in relation to the outer diameter (OD) of the tracheal tube (TT) or its cuff balloon, or limited freedom to manually maneuver the flexible bronchoscope with the TT mounted above the SGA. $^{8-12}$ A structured overview of dimensional compatibilities is essential for the success and safety of flexible bronchoscope-guided intubation through SGAs and impacts the selection of equipment, which is particularly important in emergency situations. Several studies have investigated the feasibility of the technique and differences between different SGAs as conduits for flexible bronchoscope-guided intubation with regard to success and intubation times. ${ }^{7,13-16}$
The most recent summary of dimensional limitations was reported ten years ago and was limited to a number of first-generation SGAs. ${ }^{17}$ Since then, several new disposable first- and second-generation SGAs have been introduced to the market. Newer comprehensive studies reporting dimensional limitations of SGAs as conduits for tracheal intubation exist only for children, and data for adults are missing. ${ }^{8,12}$

The aim of this study was to investigate dimensional compatibilities and limitations of different brands and sizes of TTs used in adults for flexible bronchoscope-guided tracheal intubation through different brands and sizes of disposable SGAs.

\section{Methods}

This was a laboratory-based in vitro study dedicated to the testing of various TT-SGA combinations for intubation in a bench-based approach, and the testing of various TT-SGA combinations for intubation in a mannequin, namely the Laerdal Airway Management Trainer (Laerdal Medical, AS, Stavanger, Norway).

Thirteen brands of TTs with IDs of $6.5-8.0 \mathrm{~mm}$ (four different sizes) as well as five first-generation and five second-generation disposable SGAs \#4 and \#5 were ordered in 2019 and used for this study (Table 1). Selection was based on commonly used and locally available types of SGA and TT. The maximal ID of the TTs that fit through a specific SGA, as indicated by the manufacturer (product brochures, internet information), are summarized in Table 2. For the SGA air-Q ${ }^{\circledR}$ Blocker (Cookgas ${ }^{\circledR}$, Saint Louis, MO, USA), sizes \#3.5 and \#4.5 were used as they best correspond to sizes \#4 and \#5 of other SGA models. For the SGA iLTS-D® (VBM Medizintechnik GmbH, Sulz a. N., Germany), size \#4.5 was used, corresponding to size \#4 and size \#5 of other SGA models. Outer diameters of 13 brands and four TT sizes as provided by the manufacturer are summarized in the Appendix. The lengths of all included brands and the sizes of TTs were measured without connector.

For in vitro dimensional feasibility testing of tracheal intubation through SGAs, a single-use flexible bronchoscope (aScope ${ }^{\mathrm{TM}} 4$ Broncho Regular endoscope; OD, 5.0/5.4 mm; length, $600 \mathrm{~mm}$; working channel width, $2.2 \mathrm{~mm}$; Ambu A/S, Ballerup, Denmark) and an intubation mannequin (Laerdal Airway Management Trainer, Adult; Laerdal Medical, AS, Stavanger, Norway) were used.

Tracheal tubes and SGAs were assessed in the following three in vitro experimental setups: 
TABLE 1 Supraglottic airway devices and tracheal tubes used in this study

\begin{tabular}{|c|c|c|c|c|c|c|}
\hline SGA brand name & Study name & Generation & \multicolumn{2}{|c|}{ Reference number } & \multicolumn{2}{|c|}{ Manufacturer, location, country } \\
\hline air-Q® Blocker & air-Q & $1^{\text {st }}$ & \multicolumn{2}{|l|}{3045} & \multicolumn{2}{|c|}{ Cookgas ${ }^{\circledR}$, Saint Louis, MO, USA } \\
\hline $\mathrm{Ambu}{ }^{\circledR}$ Aura-i ${ }^{\mathrm{TM}}$ & Aura-i & $1^{\text {st }}$ & \multicolumn{2}{|c|}{329500000} & \multicolumn{2}{|c|}{ Ambu A/S, Ballerup, Denmark } \\
\hline Ambu ${ }^{\circledR}$ Aura Once ${ }^{\mathrm{TM}}$ & AuraOnce & $1^{\text {st }}$ & \multicolumn{2}{|c|}{321500000} & \multicolumn{2}{|c|}{ Ambu A/S, Ballerup, Denmark } \\
\hline LMA ${ }^{\circledR}$ Unique $^{\mathrm{TM}}$ & Unique & $1^{\text {st }}$ & \multicolumn{2}{|c|}{125050} & \multicolumn{2}{|c|}{ Teleflex Medical, Athlone, Ireland } \\
\hline Portex ${ }^{\circledR}$ Soft Seal & Portex & $1^{\text {st }}$ & \multicolumn{2}{|c|}{$100 / 220 / 500$} & \multicolumn{2}{|c|}{ Smith Medical, Kent, United Kingdom } \\
\hline Ambu ${ }^{\circledR}$ AuraGain $^{\mathrm{TM}}$ & AuraGain & $2^{\text {nd }}$ & \multicolumn{2}{|c|}{408500000} & \multicolumn{2}{|c|}{ Ambu A/S, Ballerup, Denmark } \\
\hline i-gel ${ }^{\circledR}$ & i-gel & $2^{\text {nd }}$ & \multicolumn{2}{|c|}{8205000} & \multicolumn{2}{|r|}{ Intersurgical GmbH, Sankt Augustin, Germany } \\
\hline iLTS-D® & iLTS & $2^{\text {nd }}$ & \multicolumn{2}{|c|}{$32-08-045-1$} & \multicolumn{2}{|r|}{ VBM Medizintechnik GmbH, Sulz a. N., Germany } \\
\hline LarySeal $^{\mathrm{TM}}$ Pro & LarySeal & $2^{\text {nd }}$ & \multicolumn{2}{|c|}{$038-94-850$} & \multicolumn{2}{|c|}{ Flexicare Irvine, CA, USA } \\
\hline LMA ${ }^{\circledR}$ Protector $^{\mathrm{TM}}$ & Protector & $2^{\text {nd }}$ & \multicolumn{2}{|c|}{192050} & \multicolumn{2}{|c|}{ Teleflex Medical, Athlone, Ireland } \\
\hline \multicolumn{2}{|l|}{ TT brand name } & \multicolumn{2}{|l|}{ Study name } & \multicolumn{3}{|c|}{ Reference number Manufacturer, location, country } \\
\hline \multicolumn{2}{|c|}{ Covidien Mallinckrodt ${ }^{\mathrm{TM}}$ Hi-Contour } & \multicolumn{2}{|l|}{ Mallinckrodt } & $107-80$ & & Covidien, Athlone, Ireland \\
\hline \multicolumn{2}{|c|}{ Covidien Mallinckrodt $^{\mathrm{TM}}$ Safetyflex ${ }^{\mathrm{TM}}$} & \multicolumn{2}{|c|}{ Mallinckrodt Reinforced } & $118-80 \mathrm{M}$ & & Covidien, Athlone, Ireland \\
\hline Intersurgical InTube $\mathrm{TM}^{\mathrm{TM}}$ & & \multicolumn{2}{|c|}{ Intersurgical } & 8040080 & & Intersurgical Ltd, Wokingham, Berkshire, UK \\
\hline Intersurgical InTube ${ }^{\mathrm{TM}}$ reinforced & & \multicolumn{2}{|c|}{ Intersurgical reinforced } & 8060080 & & Intersurgical Ltd, Wokingham, Berkshire, UK \\
\hline Parker Flex-Tip ${ }^{\circledR}$ trache & ube & Parker & & I-PFHV-80 & & Parker Medical, Highlands Ranch, CO, USA \\
\hline Parker Flex-Tip ${ }^{\circledR}$ Reinf & d Tracheal Tube & Parker Reinf & & I-PFRC-80 & & Parker Medical, Highlands Ranch, CO, USA \\
\hline Rueschelit ${ }^{\circledR}$ SuperSafety & lear & Ruesch & & $112482-80$ & & Teleflex Medical, Athlone, Ireland \\
\hline Rueschflex & & Ruesch reinf & & $104202-80$ & & Teleflex Medical, Athlone, Ireland \\
\hline Portex ${ }^{\circledR}$ tracheal tube & & Portex & & $100 / 150 / 080$ & & Smith Medical, Kent, UK \\
\hline Portex ${ }^{\circledR}$ tracheal tube re & prced & Portex reinfo & & $100 / 110 / 080$ & & Smith Medical, Kent, UK \\
\hline Unomedical HiLo & & Unomedical & & UM61110080 & & ConvaTec, Deeside, Flintshire, UK \\
\hline Unomedical UnoFlex ${ }^{\mathrm{TM}}$ & & Unomedical & forced & UM61214080 & & ConvaTec, Deeside, Flintshire, UK \\
\hline Microcuff ${ }^{\circledR}$ & & Microcuff & & 35216 & & Halyard, Zaventem, Belgium \\
\hline
\end{tabular}

Disposable first- and second-generation SGAs size \#4 and \#5 as well as TTs with a sized internal diameter of 6.5-8.0 mm included in the study. SGA reference number is given for \#5 and TT reference number is given for size ID $8.0 \mathrm{~mm}$

SGA = supraglottic airway device; $\mathrm{TT}=$ tracheal tube

Experimental setup 1: TT passage through the SGA

Feasibility and ease of full insertion of the TT through the SGA with a $15-\mathrm{mm}$ connector were assessed. The only SGA whose connector could easily be removed for flexible bronchoscope-guided intubation, as indicated by the manufacturer, was the air-Q. In the air-Q, the SGA connector is designed to be removed for tracheal intubation through the SGA, while in the other SGAs, the connector is firmly inserted and can only be removed with difficulty, if at all.

Outcome parameters were as follows: easy passage, passage with resistance but possible, or passage not possible. In the case of resistance or failure to advance the TT, the maximal position of the TT tip in the lumen of the SGA was noted as follows: proximal SGA inlet, in the SGA lumen, or distal SGA outlet.

\section{Experimental setup 2: SGA removal over the TT}

We evaluated the feasibility of SGA removal over the TT by pushing the TT through the SGA with a stabilizing rod (air-Q ${ }^{\circledR}$ "removal stylet" size 1 for adults; Cookgas ${ }^{\circledR}$, Saint Louis, MO, USA). Outcome parameters were successful or unsuccessful SGA removal over the IT.

Experimental setup 3: free distance to manually operate the flexible bronchoscope between the TT tip mounted on the flexible bronchoscope and the SGA connector

We assessed the free distance for manual operation of the Ambu aScope with the TT mounted on it (Electronic Supplementary Material [ESM], eFig. 1). The flexible bronchoscope loaded with the TT was inserted through the SGA until the tip of the flexible bronchoscope was level with the vocal cords. Thereafter, the distance between the 
TABLE 2 Internal diameter of SGAs and TTs recommended by their manufacturers and measured length of SGA

\begin{tabular}{|c|c|c|c|c|c|c|c|c|}
\hline \multirow{2}{*}{$\begin{array}{l}\text { SGA } \\
\text { brand }\end{array}$} & \multicolumn{4}{|c|}{ SGA \#4 (3.5 for air-Q) } & \multicolumn{4}{|c|}{ SGA \#5 (4.5 for air-Q) } \\
\hline & $\begin{array}{l}\text { ID of } \\
\text { SGA } \\
(\mathrm{mm})\end{array}$ & $\begin{array}{l}\text { Max. ID of TT } \\
(\mathrm{mm})\end{array}$ & $\begin{array}{l}\text { Recommended for } \\
\mathrm{BW} \text { or } \mathrm{BL}\end{array}$ & $\begin{array}{l}\text { Length of } \\
\text { SGA } \\
(\mathrm{mm})\end{array}$ & $\begin{array}{l}\text { ID of } \\
\text { SGA } \\
(\mathrm{mm})\end{array}$ & $\begin{array}{l}\text { Max. ID of TT } \\
(\mathrm{mm})\end{array}$ & $\begin{array}{l}\text { Recommended for } \\
\mathrm{BW} \text { or } \mathrm{BL}\end{array}$ & $\begin{array}{l}\text { Length of SGA } \\
(\mathrm{mm})\end{array}$ \\
\hline air-Q & 14 & 7.5 & $50-70 \mathrm{~kg}$ & $172.8(0.6)$ & 15 & 8.5 & $70-100 \mathrm{~kg}$ & $186.8(1.3)$ \\
\hline Aura-i & 12.4 & 7.5 & $50-70 \mathrm{~kg}$ & $173.4(1.1)$ & 12.7 & 8 & $70-100 \mathrm{~kg}$ & $187.4(2.2)$ \\
\hline $\begin{array}{l}\text { Aura } \\
\text { Once }\end{array}$ & 9.6 & n.a. & $50-70 \mathrm{~kg}$ & $182.4(1.4)$ & 10.6 & n.a. & $70-100 \mathrm{~kg}$ & $206.5(1.5)$ \\
\hline Unique & n.a. & n.a. & $50-70 \mathrm{~kg}$ & $201.1(0.5)$ & n.a. & n.a. & $70-100 \mathrm{~kg}$ & $221.7(0.8)$ \\
\hline Portex & 11 & n.a. & $50-70 \mathrm{~kg}$ & $214.3(2.1)$ & 12 & n.a. & $70-100 \mathrm{~kg}$ & $228.9(1.6)$ \\
\hline AuraGain & 12.7 & 7.5 & $50-70 \mathrm{~kg}$ & $170.2(2.9)$ & 12.9 & 8 & $70-100 \mathrm{~kg}$ & $182.7(1.8)$ \\
\hline i-gel & 12.3 & 7 & $50-90 \mathrm{~kg}$ & $175.1(1.3)$ & 13.2 & 8 & $>90 \mathrm{~kg}$ & $184.8(2.9)$ \\
\hline iLTS & n.a. & 8 & $>155 \mathrm{~cm}$ & $191.2(0.9)$ & n.a. & 8 & $>155 \mathrm{~cm}$ & $191.2(3.2)$ \\
\hline LarySeal & n.a. & 8 & $50-70 \mathrm{~kg}$ & $156.8(1.1)$ & n.a. & 8 & $70-100 \mathrm{~kg}$ & $164.2(1.4)$ \\
\hline Protector & 13 & 7.5 & $50-70 \mathrm{~kg}$ & $180.0(3.1)$ & 13 & 7.5 & $70-100 \mathrm{~kg}$ & $194.7(2.4)$ \\
\hline
\end{tabular}

Internal diameter of SGA, maximal ID of TT recommended for potential insertion through a specific brand and size of SGA, and patient body weight or body length for selection of SGA size \#4 and \#5 as provided by the manufacturers. In addition to these data provided by the manufacturers, the mean (standard deviation) SGA length is measured in $\mathrm{mm}$ on the short side of the SGA tube including the connector (except for the connector from the air-Q, which was removed, as recommended by the manufacturer). BL = body length; BW = body weight; ID = internal diameter; n.a.= no information available; $\mathrm{SGA}=$ supraglottic airway device; $\mathrm{TT}=$ tracheal tube

*air-Q \#3.5 corresponds to SGA \#4 and air-Q \#4.5 corresponds to SGA \#5

TT tip and the upper border of the SGA connector was measured using an electronic sliding caliper (Sliding Calliper, Serie 500 - ABSOLUTE AOS Digimatic; Brütsch/Rüegger Werkzeuge AG, Urdorf, Switzerland). We considered a free distance of at least $20 \mathrm{~mm}$ desirable for good clinical performance. Accordingly, TT-SGA combinations being less than $20 \mathrm{~mm}$ or those showing negative values were assessed. Negative distances mean that the tip of the TT mounted on the flexible bronchoscope reached the SGA connector before the tip of the flexible bronchoscope entered the vocal cords.

For all experimental setups, the external surface of the TTs, the flexible bronchoscope, as well as the internal surface of the SGAs were lubricated with medical silicone spray prior to testing (Ruesch Silikonspray; Willy Ruesch $\mathrm{GmbH}$, Kernen-Rommelhausen, Germany). This was consistent with daily practice of using extensive lubrication to reduce surface frictions between the different pieces of equipment to a minimum. In our setting, lubrication was essential for differentiation of resistances and obstructions caused by dimensional incompatibility of the airway devices from those resistances caused by surface frictions between different synthetic materials. In experimental setup 1, 13 brands and four different sizes of TT were investigated in SGAs of ten different brands and two sizes (Table 1). Two TTs and SGAs (A/B) were tested for each brand and size (total, 104
TTs and 40 SGAs; 1,040 combinations). A TT with an ID of $8.0 \mathrm{~mm}$ was first passed through each SGA \#5. The same experiment was repeated while downsizing TTs by half a number until reaching size ID $6.5 \mathrm{~mm}$. Thereafter, the experiments were repeated in SGAs \#4 in the same way. Experimental setups 2 and 3 included all combinations of SGAs and TTs with possible passage of the TT through the SGA as tested in Experimental setup 1.

All measurements of SGA and TT lengths and the assessments in experimental setups 1-3 were repeated twice by two different anesthesiologists and in randomized order for TT brands and SGA brands and for each run (www.random.org). Data were recorded in Microsoft Excel (Microsoft Office Professional Plus 2013, Redmond, WA, USA). Measured and calculated distances are presented as mean (standard deviation [SD]) for tables and as mean for graphical presentation.

\section{Results}

Experimental setup $1(\mathrm{n}=1,040$ TT-SGA combinations)

We made a total of 4,160 attempts to advance a specific TT through an SGA (13 TT brands $\mathrm{x} 4$ IDs $=52$ tubes $\mathrm{x} 10$ SAD brands $\times 2$ sizes $=20=1,040$ combinations, two 
TABLE 3 Possible combinations for intubation of TTs through SGAs

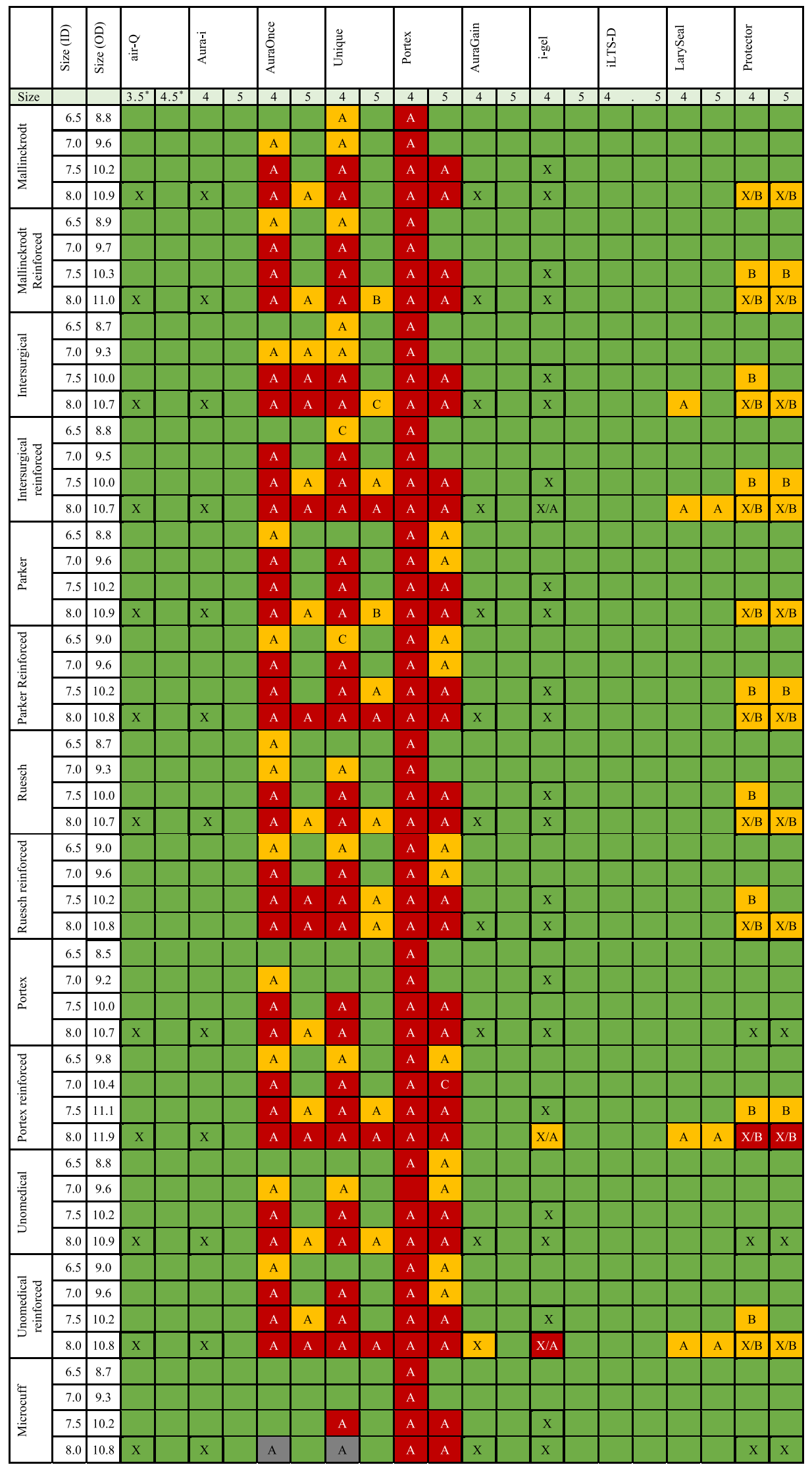


TABLE 3 continued

*air-Q \#3.5 corresponds to SGA \#4 and air-Q \#4.5 corresponds to SGA \#5

Feasibility and ease of insertion of 13 different TT brands, sizes (ID) 6.5, 7.0, 7.5, and $8.0 \mathrm{~mm}$ and (OD), through SGAs size \#4 and \#5 of different brands. TT passage through SGAs is classified as follows: green squares = easy passage; yellow squares = passage with resistance but possible; and red squares = passage not possible. Locations of resistance are classified as A for proximal SGA inlet, B for SGA tube, and C for distal SGA outlet. Squares marked with thicker lines and " $X$ " indicate a combination of TT size and SGA not recommended by the manufacturer. ID = internal diameter; OD = outer diameter; SGA = supraglottic airway device; TT $=$ tracheal tube

attempts per anesthesiologist, two anesthesiologists). Results for the four attempts performed were consistent among the two investigators for all combinations tested. Failure to pass a TT through the five first-generation SGAs tested occurred in 155 (30\%) of 520 combinations. These included 117 (46\%) combinations with SGA \#4 and 38 (15\%) combinations with SGA \#5. Failure to pass a TT through the five second-generation SGAs occurred in another three $(0.6 \%)$ of 500 combinations: two $(0.8 \%)$ combinations with SGA \#4 and one $(0.4 \%)$ combination with SGA \#5 (Table 2). The reason for failed TT passage through a first-generation SGA was consistently a toonarrow SGA connector (Table 3). The Portex SGA \#4 connector, for example, has a cone-shaped form with a measured minimal ID of $8.20 \mathrm{~mm}$, making passage of all TTs included in this study impossible (ESM, eFig. 2).

Experimental setup 2 ( $\mathrm{n}=882$ TT-SGA combinations [1,040 combinations-158 failed combinations])

Removal of the SGA over the TT was assessed in the remaining 882 combinations. Results for all four attempts performed were consistent among the two assessors for all combinations tested. Because the adapter was fixed to some TTs, its removal was not possible in all sizes of reinforced TTs except in one brand, the Parker Reinforced TT (Parker Medical, Highlands Ranch, CO, USA). For all other TTs, the SGA could be removed over the TT using the stabilizing rod (Table 4).

\section{Experimental setup 3 ( $\mathrm{n}=882$ TT-SGA combinations)}

Measured lengths of SGAs and TTs are summarized in Table 2 and Table 5, respectively. The free distance for manual guidance of the flexible bronchoscope between TT tip and SGA connector ranged from 18.5 to $102.0 \mathrm{~mm}$ in SGAs \#4 $(n=401)$, with just one TT-SGA combination showing a free distance of less than $20 \mathrm{~mm}$. The free distance in SGAs \#5 ranged from -30.5 to $84.0 \mathrm{~mm}(n=$ 481), with 84 (18\%) TT-SGA combinations being less than $20 \mathrm{~mm}$ and 23 (5\%) showing negative values (Fig. 1). The latter were particularly observed in three of five brands of reinforced TTs, namely the Mallinckrodt Reinforced TT (Covidien, Athlone, Ireland), the Parker Reinforced TT (Parker Medical, Highlands Ranch, CO, USA), and the Ruesch Reinforced TT (Teleflex Medical, Athlone, Ireland). These reinforced TTs are about $20 \mathrm{~mm}$ longer than other similarly sized TTs tested (Table 5).

\section{Discussion}

This in vitro study investigated dimensional compatibilities and limitations of several currently available brands of TT and SGA for tracheal intubation by any technique (blind, flexible bronchoscope-guided, light-guided, use of the airway exchanger catheter) using an intubation mannequin. The main findings were that failure to pass the TT through the SGA occurred mainly with firstgeneration SGAs, where the TT tip became wedged mainly in the SGA connector. Removal of the SGA over the TT was generally feasible, except in four of five brands of wire-reinforced TTs because of the non-detachable TT connectors. Finally, in many combinations with SGA \#5, there was no free distance for guidance of the flexible bronchoscope between TT tip and SGA connector.

Tracheal tube passage through the SGA

Our findings concerning TT sizes for possible passage through the SGA were not in full agreement with recommendations given by the manufacturers, as seen in Table 3, shown by the white squares with an $\mathrm{X}$. We found that some combinations were possible with easy passage of a TT with a larger ID $(8.0 \mathrm{~mm}$ and $7.5 \mathrm{~mm})$ than recommended by the manufacturer, in two first-generation SGAs \#4 and another two second-generation SGAs. The first-generation SGAs Portex (Smith Medical, Kent, UK), Aura Once (Ambu A/S, Ballerup, Denmark), and Unique (Teleflex Medical, Athlone, Ireland) are associated with a high rate of failed TT passage through the SGA, except for some in combination with a TT size ID 6.5. This is in accordance with previous clinical reports using these firstgeneration devices with either TTs size ID 6.0 or an 
TABLE 4 Feasibility of removal of different TTs through different SGAs

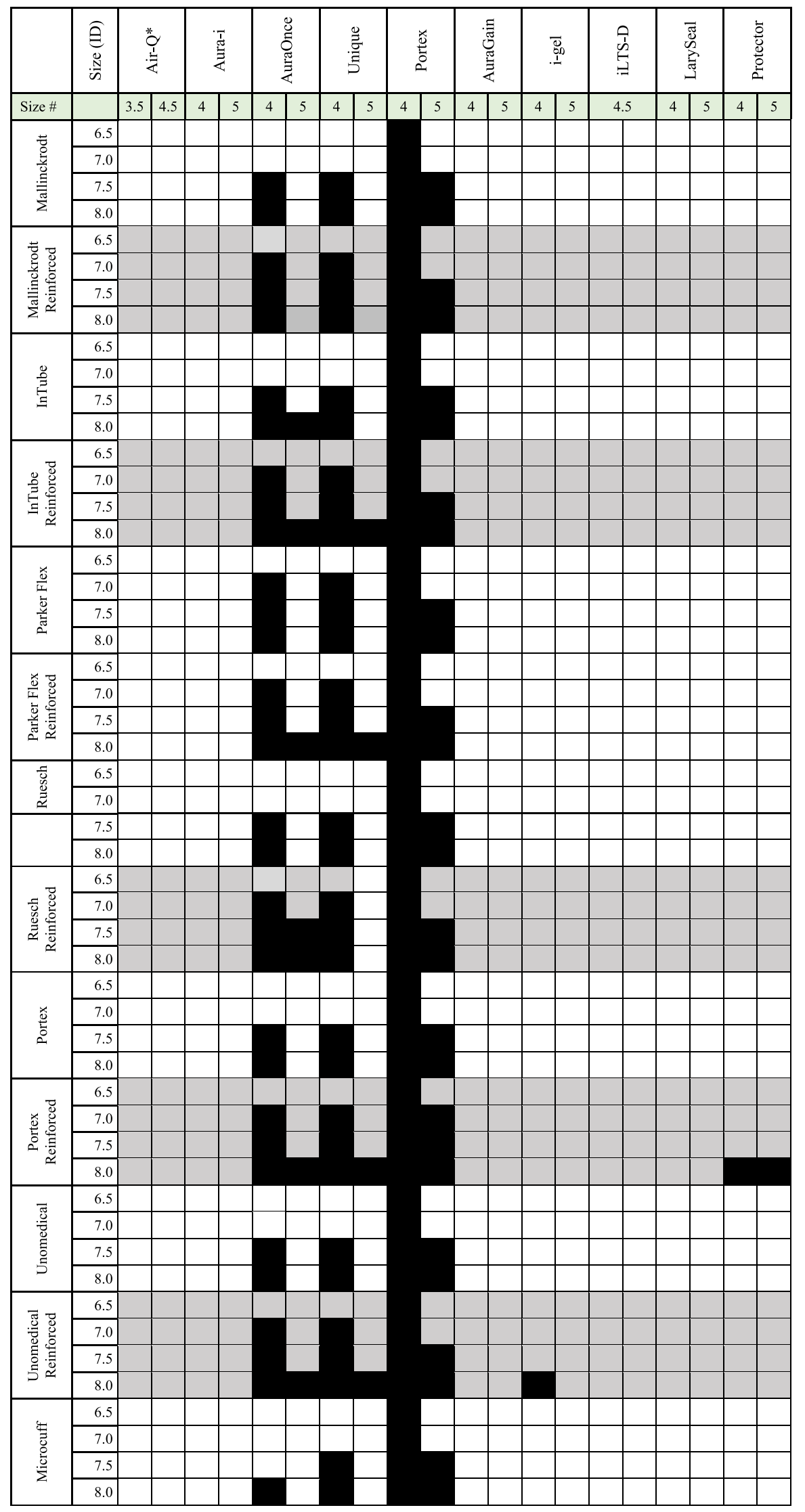


TABLE 4 continued

Summarized are the results for SGAs size \#4 and \#5 of ten different brands over TTs of 13 different brands, sizes (ID) 6.5, 7.0, 7.5 and 8.0 mm, by pushing the TT with a stabilizing rod. Black squares: assessment excluded because passage of TT through SGA was not possible in Experimental setup 1 ; white squares $=$ SGA removal over the TT possible; grey squares $=$ TT adapter not able to be removed from the TT. $*$ air-Q \#3.5 corresponds to SGA \#4 and air-Q ${ }^{\circledR} \# 4.5$ corresponds to SGA \#5. ID = internal diameter; SGA = supraglottic airway device; TT = tracheal tube

TABLE 5 Lengths of TTs studied

$$
\text { Length of TT Length of TT Length of TT Length of TT }
$$

ID $6.5 \mathrm{~mm} \quad$ ID $7.0 \mathrm{~mm} \quad$ ID $7.5 \mathrm{~mm} \quad$ ID $8.0 \mathrm{~mm}$

$\begin{array}{lllll}\text { Mallinckrodt } & 295.5(0.5) & 306.8(0.2) & 316.5(0.1) & 331.4(0.2) \\ \begin{array}{l}\text { Mallinckrodt } \\ \text { Reinforced }\end{array} & 321.3(0.3) & 328.1(0.5) & 347.7(0.3) & 346.2(0.3) \\ \begin{array}{l}\text { Intersurgical } \\ \text { Intersurgical }\end{array} & 312.9(0.3) & 326.1(0.2) & 336.0(0.3) & 336.0(0.2) \\ \text { reinforced } & 330.1(0.2) & 331.8(0.2) & 332.3(0.2) & 338.4(0.1) \\ \text { Parker } & 295.3(0.1) & 313.4(0.4) & 315.3(0.1) & 330.5(0.2) \\ \text { Parker Reinforced } & 314.7(0.1) & 325.0(0.3) & 341.8(0.1) & 350.0(0.1) \\ \text { Ruesch } & 301.7(0.3) & 317.9(0.2) & 333.2(0.2) & 343.3(0.1) \\ \text { Ruesch reinforced } & 335.7(0.2) & 347.3(0.2) & 353.5(0.2) & 357.8(0.1) \\ \text { Portex } & 302.7(0.1) & 306.4(0.3) & 311.9(0.2) & 328.2(0.1) \\ \text { Portex reinforced } & 301.8(0.4) & 313.4(0.3) & 324.2(0.4) & 333.5(0.3) \\ \text { Unomedical } & 299.3(0.4) & 311.7(0.2) & 318.0(0.3) & 331.1(0.2) \\ \begin{array}{l}\text { Unomedical } \\ \text { reinforced }\end{array} & 300.2(0.2) & 307.6(0.3) & 315.2(0.2) & 336.9(0.1) \\ \text { Microcuff } & 292.4(0.2) & 303.9(0.2) & 313.9(0.4) & 324.3(0.1)\end{array}$

Measured lengths without connector of the 13 brands and four sizes of TT. Lengths are mean (standard deviation) and given in mm. ID = internal diameter; $\mathrm{TT}=$ tracheal tube

Aintree exchange catheter for intubation (COOK MEDICAL LLC, Bloomington, IN, USA). ${ }^{18,19}$ Others have also pointed out that limitations exist for these SGAs regarding TT ID and TT length. ${ }^{17,20}$ Apart from the ID and the length of the airway tube of these SGAs, the angulation and the bars at the SGA opening were also reported to hinder intubation. ${ }^{19}$ As the design of most of the older first-generation SGAs is similar to the one of the LMA ${ }^{\circledR}$ Classic $^{\mathrm{TM}}$ Airway (LMA; Teleflex Medical, Athlone, Ireland) that was designed for ventilation and not for intubation, this finding was not surprising.
Accordingly, no information is available from the manufacturer with regard to TT size able to fit through the SGA. The higher failure rate for reinforced TTs can likely be explained by their larger OD in some brands and sizes (Appendix). In contrast, the two first-generation SGAs, air-Q and Aura-i (Ambu A/S, Ballerup, Denmark), especially designed for flexible bronchoscope tracheal intubation through the SGA, feature an increased ID of the SGA lumen and shortened length of the SGA tube, resulting in improved compatibilities. 
Of note, almost all combinations with second-generation devices permitted passage of the TT through the SGA, although they include an additional gastric channel. Our findings show that they have in general an increased ID of the SGA lumen and are generally shorter than firstgeneration devices (Table 2). Following the recommendations of current difficult airway guidelines that recommend using second-generation instead of firstgeneration SGAs (DAS, ASA), the risk posed by incompatible combinations of SGA and TT would significantly reduce. ${ }^{1,2}$ Nevertheless, despite the guidelines, first-generation SGAs are still widely used. This stands in contrast to children, where dimensional incompatibilities persist even with second-generation SGAs. $^{8}$ The small IDs of pediatric SGAs mean that many combinations of SGA and TT were incompatible, particularly in the small SGA sizes combined with cuffed TTs. ${ }^{8}$

\section{Supraglottic airway device removal over the TT}

In general, it has been shown that SGAs do not need to be removed for shorter operations when a TT is placed over an SGA, which does not increase throat soreness or hoarseness. ${ }^{13-15}$ In children, there even exists a clear recommendation to leave the SGA in place when challenged with a difficult airway. ${ }^{21}$ Another option is to insert a tube exchanger into the trachea over the SGA and then remove the SGA over the inserted tube exchanger and subsequently advance the TT over the airway exchanger. $^{22,23}$

Removal of the SGA may, however, become necessary in the case of oro-maxillary interventions as well as when transferring the patient to the intensive care unit for postoperative ventilation. To remove the SGA over the TT, the TT connector needs to be removed, which is not always possible with reinforced TTs often used for flexible bronchoscope-guided intubation because of their easy passage and the possibility to follow the curves of the bronchoscope. In contrast to cuffed pediatric TTs, in which the cuff pilot balloon was shown to be bigger than the ID of pediatric SGAs (particularly sizes 1 and 1.5), thus making it impossible to remove the SGA over the $\mathrm{TT}^{7}{ }^{7}$ the pilot balloon was not a reason for failed passage in the tested adult sizes. The major factor inhibiting removal of the TTs in the present study was the TT connector that is firmly attached to most reinforced TTs.

Free distance for manual guidance of the flexible bronchoscope between TT tip and SGA connector

In our clinical judgement, a minimal distance of $20 \mathrm{~mm}$ between the TT tip and the connector of the SGA seems to be required for manual handling/guidance of the flexible bronchoscope, at least to or through the level of the vocal cords (ESM, eFig. 1). In 85 combinations of TT and SGA, there was no free space, and in many more combinations less than $20 \mathrm{~mm}$ were available. This was mainly related to longer tubes (in particular reinforced TTs) and to SGAs \#5. Reduced free space for manipulation of the flexible bronchoscope above the SGA connector hampers rotation and forward-backward guidance of the flexible bronchoscope. Since flexible bronchoscopes are rarely longer than $600 \mathrm{~mm}$, the TT may be inserted into the SGA without protruding from the distal SGA lumen tube and the flexible bronchoscope can then be manipulated from above the TT connector. ${ }^{24}$ The difficulty caused by not having enough space in which to guide the flexible bronchoscope will be increased with greater SGA length, mostly from first-generation SGAs, as seen in Table 2. Finally, a "perfect" SGA-TT combination for flexible bronchoscope intubation is a balance of optimal TT length and SGA length, since, on the one hand, longer TTs include the risk of reduced maneuverability of the flexible bronchoscope above the SGA connector and, on the other hand, shorter TTs entail the risk of the cuff being placed in the subglottic region or even between the vocal cords. $^{24}$ It is important to remember that the original technique described by the manufacturer for flexible bronchoscope-guided intubation through the LMA ${ }^{\circledR}$ Fastrach $^{\mathrm{TM}}$ (Teleflex Medical, Athlone, Ireland) was by placing the TT through the tube of the SGA until the tip of the TT was near the exiting aperture of the SGD. ${ }^{25}$ The TT subsequently was inserted into the trachea under flexible bronchoscopic control. If the minimal distance between the TT tip and the connector of the SGA is less than $20 \mathrm{~mm}$, this could be a possible solution.

The implications of our findings are that specific lists or tables for the selection of dimensionally compatible equipment for possible flexible bronchoscope-guided or "blind" intubation through SGAs or even sets with compatible equipment should be available wherever patients are anesthetized. This is of particular importance in emergency situations, where time for adequate planning and for choosing compatible equipment is limited. Special caution must be given to wire-enforced TTs, which may fail to pass through the SGA, may fail SGA removal and may fail to allow a free distance for manipulation of the flexible bronchoscope above the SGA connector, particularly in SGA\#5. Wire-enforced tubes are therefore not the first choice of TT for intubation through SGAs. Alternatively, a special set could be prepared institutionally or developed in collaboration with the manufacturer, as was previously the case with the intubating laryngeal mask airway including a special TT with long cuff inflation line, stabilizing rod, and an SGA with sufficient ID. ${ }^{26,27}$ Currently, this is only 


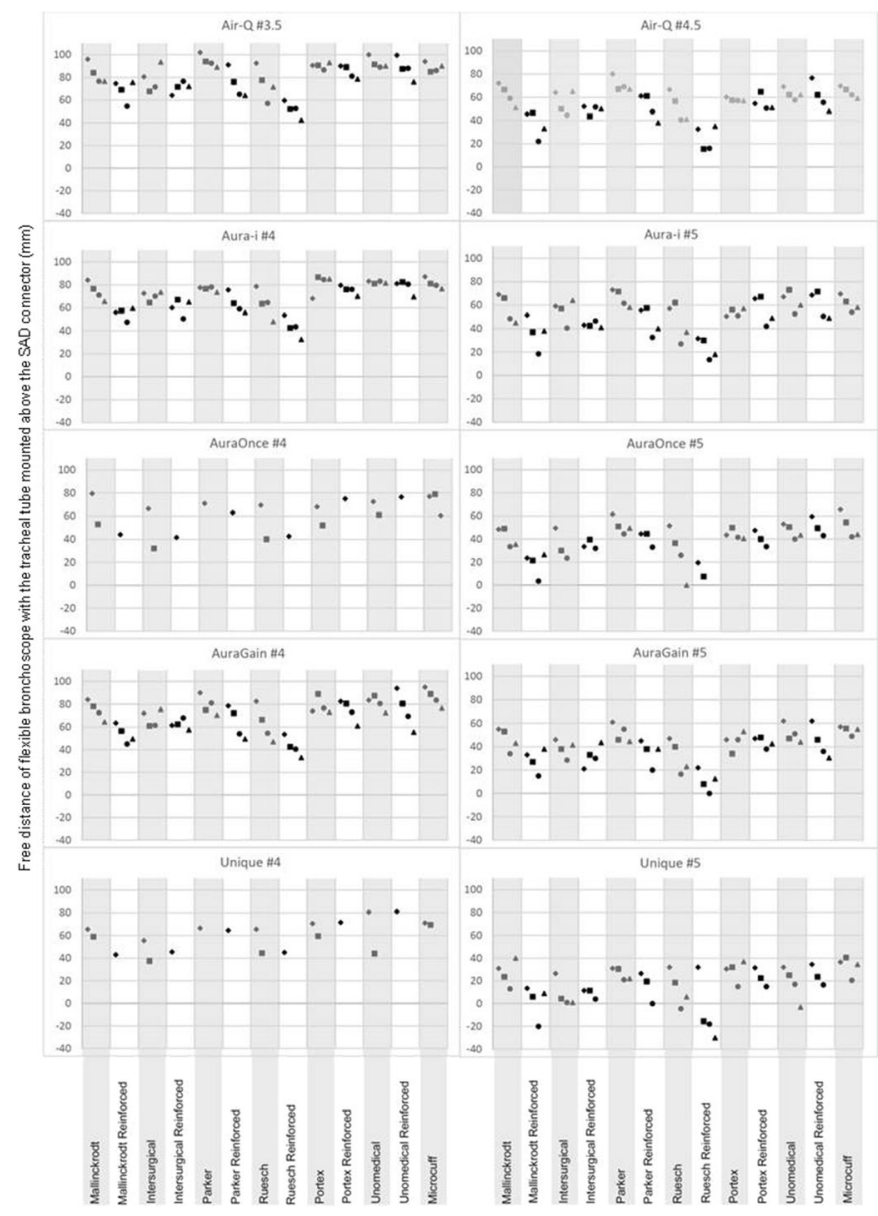

Fig. 1 Free distances above the SGA connector for manual guidance of the Ambu aScope flexible bronchoscope (length, $600 \mathrm{~mm}$ ) with the TT mounted and the tip of the flexible bronchoscope placed level with the vocal cords using 13 TT brands, ID sizes $6.5(\bullet), 7.0(\mathbf{\square}), 7.5(\cdot)$ and $8.0 \mathrm{~mm}(\boldsymbol{\Delta})$ through SGAs of ten different brands, size \#4 and \#5.

provided in the newly marketed air-Q SGA with a considerably shortened SGA tube, removable SGA adapter, and different sizes of pushing rods.

For the current study, the following limitations are to be considered. The data are from an in vitro assessment. This might not fully reflect the situation in human patients in vivo. It does, however, provide similar and therefore comparable conditions for all TT and SGA combinations tested. While assessment of passage and removal is not affected by the in vitro design of this study, the position of the SGA within the mannequin may differ from that in individual patients. Nevertheless, in contrast to human studies with anatomical differences between patients, it can be assumed that the position of the SGA in a mannequin is largely the same. Therefore, assessment of the free distance

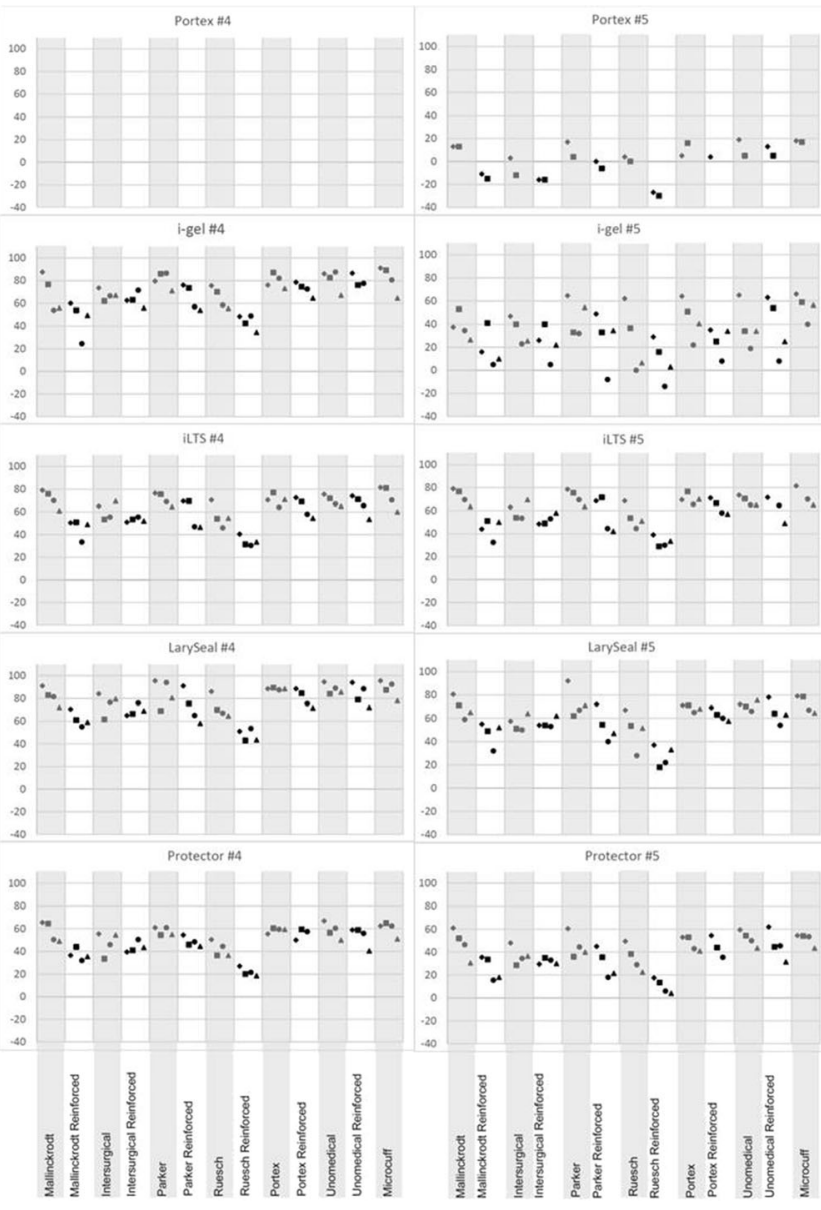

Negative values indicate a TT tip placed within the SGA connector or even deeper in the SGA lumen. Missing values indicate combinations with no possible TT passage through a specific SGA. Values are means. ID = internal diameter; SGA = supraglottic airway device; TT $=$ tracheal tube

for manipulating the flexible bronchoscope allows combinations to be identified that are critical to the free distance available for manipulating the flexible bronchoscope. Finally, while this study included a comprehensive selection of commonly used SGAs and TTs, we acknowledge there might be other combinations with good compatibility or dimensional limitations that we have not investigated.

In conclusion, the current comprehensive update on in vitro dimensional compatibilities between a selection of SGAs and TTs shows that for adult sizes too, there exist many incompatible combinations, rendering tracheal intubation through these SGAs impossible. This was particularly the case with several first-generation SGAs and with wire-reinforced TTs. 
Author contributions Berthold Moser contributed to the conception and design of study, development of methodology, data measurement and collection, analysis and interpretation of data, drafting of article, and final approval of manuscript. Michael Kemper contributed to the design of the study, development of methodology, collection of data, analysis and interpretation of data, and final approval. Maren KleineBrueggeney contributed to the development of methodology, drafting and critical revision, and final approval. Lukas Gasteiger contributed to the design of the study, statistics, analysis, critical revision, and final approval. Markus Weiss contributed to the design of the study, development of methodology, analysis and interpretation of data, revision of article, and final approval.

Funding Open access funding provided by University of Innsbruck and Medical University of Innsbruck.

\section{Disclosures None.}

Funding statement This project was supported only by departmental resources.

Editorial responsibility This submission was handled by Dr. Stephan K.W. Schwarz, Editor-in-Chief, Canadian Journal of Anesthesia/ Journal canadien d'anesthésie.
Open Access This article is licensed under a Creative Commons Attribution-NonCommercial 4.0 International License, which permits any non-commercial use, sharing, adaptation, distribution and reproduction in any medium or format, as long as you give appropriate credit to the original author(s) and the source, provide a link to the Creative Commons licence, and indicate if changes were made. The images or other third party material in this article are included in the article's Creative Commons licence, unless indicated otherwise in a credit line to the material. If material is not included in the article's Creative Commons licence and your intended use is not permitted by statutory regulation or exceeds the permitted use, you will need to obtain permission directly from the copyright holder. To view a copy of this licence, visit http://creativecommons.org/licenses/ by-nc/4.0/.

\section{Appendix: Outer diameter of TT as indicated by the manufacturer (mm) for TT ID)}

\begin{tabular}{|c|c|c|c|c|}
\hline & OD of TT ID $6.5 \mathrm{~mm}$ & OD off TT ID $7.0 \mathrm{~mm}$ & OD of TT ID $7.5 \mathrm{~mm}$ & OD off TT ID $8.0 \mathrm{~mm}$ \\
\hline Mallinckrodt & 8.8 & 9.6 & 10.2 & 10.9 \\
\hline Mallinckrodt Reinforced & 8.8 & 9.6 & 10.2 & 11.0 \\
\hline Intersurgical & 8.7 & 9.3 & 10.0 & 10.7 \\
\hline Intersurgical reinforced & 8.8 & 9.5 & 10.0 & 10.7 \\
\hline Parker & 8.8 & 9.6 & 10.2 & 10.9 \\
\hline Parker Reinforced & 9.0 & 9.6 & 10.2 & 10.8 \\
\hline Ruesch & 8.7 & 9.3 & 10.0 & 10.7 \\
\hline Ruesch reinforced & 9.0 & 9.6 & 10.2 & 10.8 \\
\hline Portex & 8.5 & 9.2 & 10 & 10.7 \\
\hline Portex reinforced & 9.8 & 10.4 & 11.1 & 11.9 \\
\hline Unomedical & 8.7 & 9.3 & 10.0 & 10.7 \\
\hline Unomedical reinforced & 8.9 & 9.7 & 10.3 & 10.8 \\
\hline Microcuff & 8.7 & 9.3 & 10.2 & 10.8 \\
\hline
\end{tabular}

ID = internal diameter; OD = outer diameter; $\mathrm{TT}=$ tracheal tubes 


\section{References}

1. Apfelbaum JL, Hagberg CA, Caplan RA, et al. Practice guidelines for management of the difficult airway: an updated report by the American Society of Anesthesiologists Task Force on Management of the Difficult Airway. Anesthesiology 2013; 118: 251-70.

2. Frerk C, Mitchell VS, McNarry AF, et al. Difficult Airway Society 2015 guidelines for management of unanticipated difficult intubation in adults. Br J Anaesth 2015; 115: 827-48.

3. Pennant $J H$, White $P F$. The laryngeal mask airway. Its uses in anesthesiology. Anesthesiology 1993; 79: 144-63.

4. Duckett J, Fell P, Han K, Kimber C, Taylor C. Introduction of the I-gel supraglottic airway device for prehospital airway management in a UK ambulance service. Emerg Med J 2014; 31: 505-7.

5. Theiler L, Kleine-Brueggeney M, Urwyler $N$, Graf $T$, Luyet $C$, Greif $R$. Randomized clinical trial of the $\mathrm{i}-\mathrm{gel}^{\mathrm{TM}}$ and Magill tracheal tube or single-use ILMA ${ }^{\mathrm{TM}}$ and ILMA $^{\mathrm{TM}}$ tracheal tube for blind intubation in anaesthetized patients with a predicted difficult airway. Br J Anaesth 2011; 107: 243-50.

6. Timmermann A. Supraglottic airways in difficult airway management: successes, failures, use and misuse. Anaesthesia 2011; 66(Suppl 2): 45-56.

7. Kleine-Brueggeney $M$, Theiler L, Urwyler $N$, Vogt A, Greif $R$. Randomized trial comparing the i-gel and Magill tracheal tube with the single-use ILMA and ILMA tracheal tube for fibreopticguided intubation in anaesthetized patients with a predicted difficult airway. Br J Anaesth 2011; 107: 251-7.

8. Kleine-Brueggeney $M$, Kotarlic $M$, Theiler $L$, Greif $R$. Limitations of pediatric supraglottic airway devices as conduits for intubation - an in vitro study. Can J Anesth 2018; 65: 14-22.

9. Mauch J, Haas T, Weiss M. Distance from the laryngeal mask grip to endotracheal tube tip. A crucial point during fiberoptic intubation in children (German). Anaesthesist 2012; 61: 123-8.

10. Weiss $M$, Gerber AC, Schmitz A. Continuous ventilation technique for laryngeal mask airway (LMA) removal after fiberoptic intubation in children. Paediatr Anaesth 2004; 14: 936-40.

11. Weiss M, Goldmann K. Caution when using cuffed tracheal tubes for fibreoptic intubation through paediatric-sized laryngeal mask airways. Acta Anaesthesiol Scand 2004. DOI: https://doi.org/10. 1111/j.1399-6576.2004.00358d.x.

12. Weiss M, Mauch J, Becke K, Schmidt J, Johr M. Fibre opticassisted endotracheal intubation through the laryngeal mask in children (German). Anaesthesist 2009; 58: 716-21.

13. Moser B, Audige L, Keller C, Brimacombe J, Gasteiger L, Bruppacher HR. A prospective, randomized trial of the Ambu AuraGain ${ }^{\mathrm{TM}}$ laryngeal mask versus the LMA protector airway in paralyzed, anaesthetized adult men. Minerva Anestesiol 2018; 84: 684-92.

14. Moser B, Audige L, Keller C, Brimacombe J, Gasteiger L, Bruppacher HR. Flexible bronchoscopic intubation through the
AuraGain ${ }^{\mathrm{TM}}$ laryngeal mask versus a slit Guedel tube: a noninferiority randomized-controlled trial. Can J Anesth 2017; 64: 1119-28.

15. Moser B, Keller C, Audige L, Dave MH, Bruppacher HR. Fiberoptic intubation of severely obese patients through supraglottic airway: a prospective, randomized trial of the Ambu® ${ }^{\circledR}$ AuraGain $^{\mathrm{TM}}$ laryngeal mask vs the $\mathrm{i}-\mathrm{gel}^{\mathrm{TM}}$ airway. Acta Anaesthesiol Scand 2019; 63: 187-94.

16. Gasteiger L, Oswald E, Keplinger $M$, et al. Arandomised trial comparing the Ambu ${ }^{\circledR}$ Aura- $\mathrm{i}^{\mathrm{TM}}$ and the Ambu ${ }^{\circledR}$ Aura Gain ${ }^{\mathrm{TM}}$ laryngeal mask as conduit for tracheal intubation in children. Minerva Anestesiol 2020; 86: 1143-50.

17. Takenaka I, Aoyama K. Optimizing endotracheal tube size and length for tracheal intubation through single-use supraglottic airway devices. Can J Anesth 2010; 57: 389-90.

18. Atherton $D P, O$ 'Sullivan $E$, Lowe $D$, Charters $P$. A ventilationexchange bougie for fibreoptic intubations with the laryngeal mask airway. Anaesthesia 1996; 51: 1123-6.

19. Danha RF, Thompson JL, Popat MT, Pandit JJ. Comparison of fibreoptic-guided orotracheal intubation through classic and single-use laryngeal mask airways. Anaesthesia 2005; 60: 184-8.

20. Wong DT, McGuire GP. Endotracheal intubation through a laryngeal mask/supraglottic airway. Can J Anesth 2007; 54: 489-91.

21. Black AE, Flynn PE, Smith HL, et al. Development of a guideline for the management of the unanticipated difficult airway in pediatric practice. Paediatr Anaesth 2015; 25: 346-62.

22. Kemper $M$, Haas $T$, Imach $S$, Weiss $M$. Intubation with a tube exchanger on an intubation trainer. Influence of tube tip position on successful intubation (German). Anaesthesist 2014; 63: 563-7.

23. Higgs A, McGrath BA, Goddard $C$, et al. Guidelines for the management of tracheal intubation in critically ill adults. $\mathrm{Br} \mathrm{J}$ Anaesth 2018; 120: 323-52.

24. Lee JH, Park S, Jang YE, Kim EH, Kim HS, Kim JT. The distance between the glottis and the cuff of a tracheal tube placed through three supraglottic airway devices in children: a randomised controlled trial. Eur J Anaesthesiol 2019; 36: 721-7.

25. Teleflex®. INSTRUCTIONS FOR USE - LMA FastrachTM. In: Teleflex Medical IDA Business and Technology Park Dublin Road ACW, Ireland. Teleflex Medical; 2015.

26. Brain AI, Verghese C, Addy EV, Kapila A. The intubating laryngeal mask. I: development of a new device for intubation of the trachea. Br J Anaesth 1997; 79: 699-703.

27. Sudheesh K, Chethana GM, Chaithali H, Nethra SS, Devikarani $D$, Shwetha $G$. A new second-generation supraglottic airway device $\left(A m b u{ }^{\circledR}\right)$ AuraGain) versus intubating laryngeal mask airway as conduits for blind intubation - a prospective, randomised trial. Indian J Anaesth 2019; 63: 558-64.

Publisher's Note Springer Nature remains neutral with regard to jurisdictional claims in published maps and institutional affiliations. 